Journal of Bangladesh Academy of Sciences, Vol. 35, No. 2, 229-235, 2011

\title{
EFFECTS OF Cd ON PHYSICAL AND SOME MAGNETIC PROPERTIES OF Co-Cd FERRITES
}

\author{
SAROAUT NOOR ${ }^{*}$, S.S. SIKDER, M. SAMIR ULLAH ${ }^{1}$, M.A. HAKIM ${ }^{2}$ AND \\ SHIREEN AKHTER ${ }^{2}$ \\ Department of Physics, Khulna University of Engineering and Technology, Khulna-9203, \\ Bangladesh
}

\begin{abstract}
Polycrystalline samples of $\mathrm{Cd}$ substituted cobalt ferrites with composition $\mathrm{Co}_{1-\mathrm{x}} \mathrm{Cd}_{\mathrm{x}} \mathrm{Fe}_{2} \mathrm{O}_{4}(\mathrm{x}=$ 0.0 - 0.6 in steps of 0.1 ) were prepared by double sintering ceramic method. The samples were sintered at $1050^{\circ} \mathrm{C}$ for 3 hours. X-ray diffraction pattern of the samples showed single phase cubic spinel structure. It was found that the lattice parameter increases linearly with increasing $\mathrm{Cd}$ content following Vegard's law. The apparent density and X-ray density exhibited similar behavior. The Curie temperature $T_{c}$ has been determined from the temperature dependence of permeability. It was found that the Curie temperature continuously decreased with increasing $\mathrm{Cd}$ content and is attributed to the weakening of $\mathrm{J}_{\mathrm{AB}}$ exchange interaction. The initial permeability, $\mu$ ' increases with increasing $\mathrm{Cd}$ content up to $\mathrm{x}=0.6$ and then decreases.
\end{abstract}

Key words: Co-Cd ferrite, Lattice parameter, Permeability

\section{INTRODUCTION}

Ferrites play a useful role in many magnetic applications. They have been extensively investigated and are the subject of great interest from both the fundamental and the applied research point of view. The important structural, electrical and magnetic properties of these spinels are responsible for their applications in various fields specially in electronics and electrical circuits. The soft ferrites belong to an important class of magnetic materials, because of their remarkable magnetic properties, particularly in radio frequency region and show physical flexibility, high electrical resistivity, mechanical hardness and chemical stability (Augustin et al. 1993). The magnetic properties of ferrites depend on chemical composition, cation distribution, porosity, grain size etc. In ferrites the cations occupy the tetrahedral (A) and octahedral (B) sites of the cubic spinel lattice and experience competing nearest neighbour $\left(\mathrm{J}_{\mathrm{AB}}\right)$ and the next nearest neighbour $\left(\mathrm{J}_{\mathrm{AA}}\right.$ and $\mathrm{J}_{\mathrm{BB}}$ ) interactions with $\left|\mathrm{J}_{\mathrm{AB}}\right|>>\mathrm{J}_{\mathrm{BB}}>\mathrm{J}_{\mathrm{AA}}$. The magnetic properties of ferrites are strongly dependent on the type of magnetic ions residing on the $\mathrm{A}$ and $\mathrm{B}$ sites and the relative strengths of the inter $\left(\mathrm{J}_{\mathrm{AB}}\right)$ and intrasublattice $\left(\mathrm{J}_{\mathrm{BB}}, \mathrm{J}_{\mathrm{AA}}\right)$ interactions. When the $\mathrm{J}_{\mathrm{AB}}$ is

\footnotetext{
*Corresponding author: <saroautnoor@yahoo.com>.

${ }^{1}$ Department of Physics, Bangladesh University of Engineering and Technology, Dhaka-1000,

Bangladesh.

${ }^{2}$ Materials Science Division, Atomic Energy Centre, Dhaka-1000, Bangladesh.
} 
much stronger than $\mathrm{J}_{\mathrm{BB}}$ and $\mathrm{J}_{\mathrm{AA}}$ interactions, the magnetic spins have a collinear structure in which the magnetic moments on the A sublattice are antiparallel to the moments on the B sublattice. But when $\mathrm{J}_{\mathrm{BB}}$ or $\mathrm{J}_{\mathrm{AA}}$ becomes comparable with $\mathrm{J}_{\mathrm{AB}}$, it may lead to noncollinear spin structure (Yafet and Kittel 1952). Physical properties of ferrites such as density, porosity, grain size etc. are dependent on the type and amount of additives, dopants, substituents as well as sintering temperature and time. $\mathrm{CoFe}_{2} \mathrm{O}_{4}$ is generally an almost inverse ferrite in which $\mathrm{Co}^{2+}$ ions mainly occupies $\mathrm{B}$-sites and $\mathrm{Fe}^{3+}$ ions are distributed almost equally between $\mathrm{A}$ and $\mathrm{B}$ sites. $\mathrm{CdFe}_{2} \mathrm{O}_{4}$ and $\mathrm{ZnFe}_{2} \mathrm{O}_{4}$ are generally assumed to be normal spinel with all $\mathrm{Fe}^{3+}$ ions on $\mathrm{B}$-sites and all $\mathrm{Cd}^{2+}$ and $\mathrm{Zn}^{2+}$ ions on A-sites. Zinc substituted spinel ferrites showed good magnetic properties for technical applications and have been studied previously by many authors (Arulmurugan et al. 1952, Bayoumi 2007, Verma and Chatterijee 2006).

As $\mathrm{Zn}$ and $\mathrm{Cd}$ are both divalent and nonmagnetic, $\mathrm{Cd}$ substituted mixed ferrite is similarly interesting from applications point of view and has not been studied much in detail. The magnetic properties of ferrites such as permeability, magnetization, coercive field, Curie temperature are affected by composition as well as by the type of substitution, cation distribution and method of preparation. The partial replacement of nonmagnetic $\mathrm{Cd}$ ions in cobalt ferrite is expected to weaken the magnetic coupling resulting in decrease of Curie temperature. A few reports are available on mixed Co-Cd ferrites (Abdeen et al. 2002, Ghani et al. 1991). The aim of the present work is to investigate in detail the effects of substitution of $\mathrm{Cd}^{2+}$ ions in place of $\mathrm{Co}^{2+}$ ions covering a wide range of concentration on the structural and some magnetic properties of Co-Cd ferrites.

\section{MATERIALS AND METHODS}

A series of polycrystalline samples of mixed ferrites $\mathrm{Co}_{1-\mathrm{x}} \mathrm{Cd}_{\mathrm{x}} \mathrm{Fe}_{2} \mathrm{O}_{4}$ (with $\mathrm{x}=0.0-0.5$ in steps of 0.1) were prepared by the standard double sintering ceramic method at the Materials Science Division, Atomic Energy Center, Dhaka. In this method high purity oxides $(99.99 \%)$ were weighted precisely according to their molecular weight. The prepared samples were sintered at $1050^{\circ} \mathrm{C}$ for 3 hours with a microprocessor controlled muffle furnace. Phase analysis was done by X-ray diffraction using Phillps (PW 3040)

X'pert PRO X-ray diffractometer. Temperature dependence of initial permeability of the toroid samples were measured with the Hewlett Packart impedance analyzer (HP4192A).

\section{RESULTS AND DISCUSSION}

A phase analysis using X-ray diffraction technique was performed to confirm the formation of single-phase cubic spinel structure as shown in Fig. 1 with no extra lines corresponding to any other crystallographic phase. The results obtained from XRD pattern for all the samples of $\mathrm{Co}_{1-x} \mathrm{Cd}_{x} \mathrm{Fe}_{2} \mathrm{O}_{4}$ with the (hkl) values corresponding to the diffraction peaks of different planes (111), (220), (311), (222), (400), (422), (511), and 
(440) which represent either odd or even indicating the samples are spinel cubic phase. The peaks are found to shift slightly towards the lower d-spacing values.

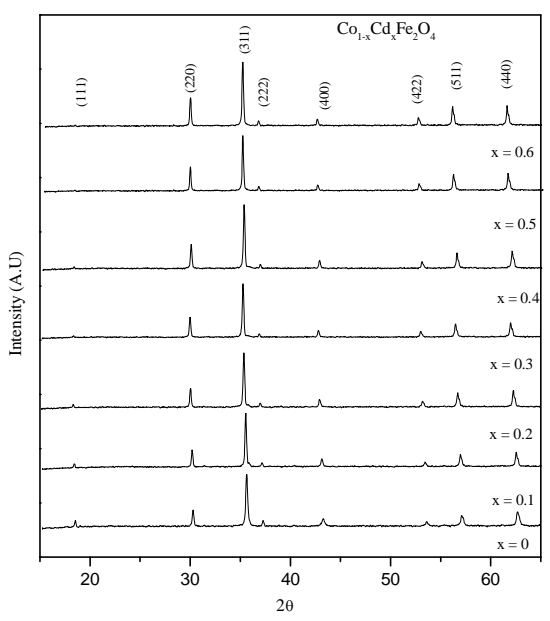

Fig. 1. XRD patterns of $\mathrm{Co}_{1-\mathrm{x}} \mathrm{Cd}_{\mathrm{x}} \mathrm{Fe}_{2} \mathrm{O}_{4}$ ferrites.

The accurate lattice parameter has been determined from the calculated lattice parameter, a corresponding to each plane of XRD pattern using Nelson-Riley function (Nelson and Riley 1945) $\mathrm{F}(\theta)=1 / 2\left(\cos ^{2} \theta / \sin \theta+\cos ^{2} \theta / \theta\right)$, where $\theta$ is the Bragg's angle, by extrapolating the lattice parameter values to $\mathrm{F}(\theta)=0$ or $\theta=90^{\circ}$.

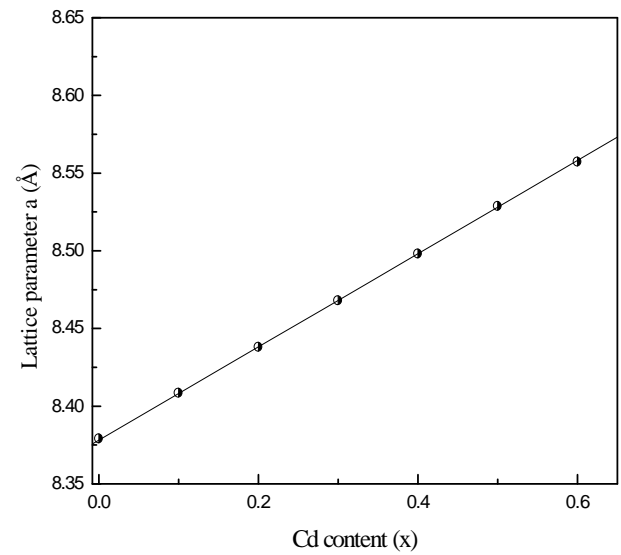

Fig. 2. Variation of lattice constant ' $a$ ' as a function of $\mathrm{Cd}$ content (x) of $\mathrm{Co}_{1-\mathrm{x}} \mathrm{Cd}_{\mathrm{x}} \mathrm{Fe}_{2} \mathrm{O}_{4}$ ferrites.

Variation of lattice parameter ' $a$ ' as a function of Cd content $\mathrm{x}$ is shown in Fig. 2 and also in Table 1. From Fig. 2 it is observed that the lattice parameter increases linearly with the increase of Cd content obeying Vegard's law (Vegard 1921). 
This enhancement of lattice parameter is attributed to $\mathrm{Cd}^{2+}$ with larger ionic radius (1.03 $)$ which replaces $\mathrm{Co}^{2+}(0.72 \AA)$ having smaller ionic radii. It is well-known that the distribution of cations on the octahedral B-sites and tetrahedral A-sites determines to a great extent the physical, electrical and magnetic properties of ferrites.

There exists a correlation between the ionic radius and the lattice constant, the increase of the lattice constant is proportional to the increase of the ionic radius (Globus et al. 1977). It is observed that the bulk density is lower than the X-ray density. This may be due to the existence of pores, which were formed and developed during the sample preparation or sintering process. The X-ray density and bulk density increase significantly with increase in $\mathrm{Cd}$ content.

Fig. 3 shows the temperature dependence of initial permeability, $\mu^{\prime}$ for the toroid shaped samples, which is measured at a constant frequency (100 kHz) of an AC signal by using Impedance Analyzer. It is observed that the initial permeability increases with the increase in $\mathrm{Cd}$ content while it falls abruptly close to the Curie point. This is because $\mathrm{Cd}$ in these compositions not only increases the magnetic moment and, but also lowers anisotropy, $K_{1}$ (Goldman 1999). On the other hand, permeability increases with the decrease of $K_{1}$ as the temperature increases according to the relation $\mu^{\prime} \infty \frac{M_{s}^{2} D}{\sqrt{K_{1}}}$

(Jain et al. 1976, Chikazumi 1966). When the anisotropy constant reaches to zero just below the Curie temperature, $\mu^{\prime}$ attains its maximum value and then drops off sharply to minimum value at the Curie point. The sharpness of the permeability drops at the Curie point can be used as a measure of the degree of compositional homogeneity (Srivastava et al. 1976) which has also been confirmed by X-ray diffraction that no impurity phases could be detected. Fig. 4 a, b represents the variation of complex permeability and temperature derivatives of permeability as a function of temperature of the sample $\mathrm{x}=0.5$.

It is observed that the imaginary part of permeability $\mu^{\prime \prime}$ and temperature derivatives of permeability, $\mathrm{d} \mu^{\prime} / \mathrm{dT}$ show peaks at temperature, $\mathrm{T}$ which excellently matches with the temperature of sharp fall of permeability at $T=T_{c}$. The $T_{c}$ values are shown in Table 1 . It is observed that Curie temperature linearly decreases with the increase of $\mathrm{Cd}$ content. The non-magnetic $\mathrm{Cd}^{2+}$ ions that replaced the magnetic $\mathrm{Fe}^{3+}$ ions on $\mathrm{A}$-sites and thus the number of $\mathrm{Fe}^{3+}$ decreases on A-sites. The decrease of $\mathrm{T}_{\mathrm{c}}$ is due to the weakening of the A$B$ exchange interaction as well as due to increase of lattice parameter with $\mathrm{Cd}^{2+}$ content which increases the distance between the magnetic cations.

The initial permeability was found to vary with $\mathrm{Cd}$ content of the ferrites. Fig. 5 shows the real $\left(\mu^{\prime}\right)$ part of the complex permeability $\mu^{\prime}=\mu_{i}^{\prime}-i \mu^{\prime \prime}$ of different compositions sintered at $\mathrm{T}_{\mathrm{s}}=1050^{\circ} \mathrm{C}$ for 3 hours as a function of frequency $\mathrm{f}$ measured at room temperature. The increase in $\mu^{\prime}$ with $\mathrm{Cd}$ content is clearly evident. 


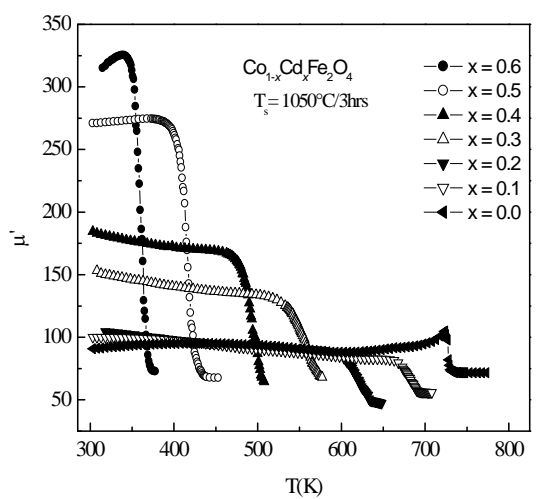

Fig. 3. Temperature dependence of permeability, $\mu^{\prime}$ of $\mathrm{Co}_{1-\mathrm{x}} \mathrm{Cd}_{\mathrm{x}} \mathrm{Fe}_{2} \mathrm{O}_{4}$ ferrites.

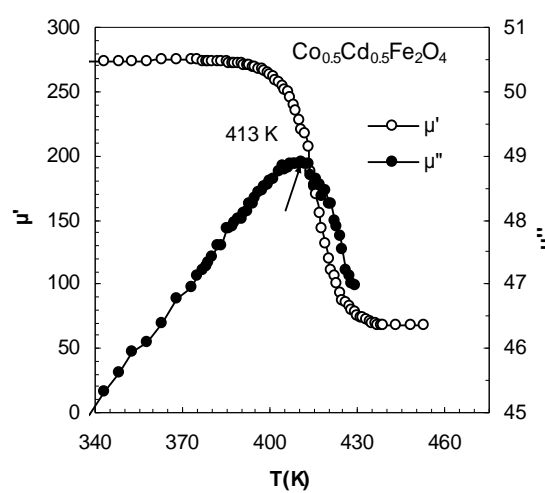

(a)

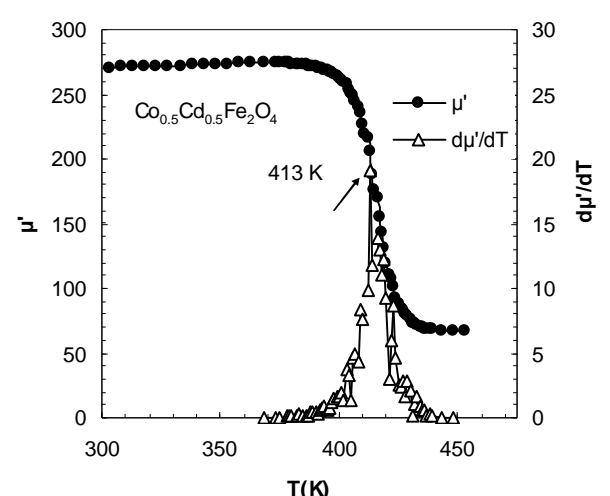

(b)

Fig. 4a, b. Determination of Curie temperature from the temperature dependence of $\mu^{\prime}$, $\mu^{\prime \prime}$ and $\mathrm{d} \mu^{\prime} / \mathrm{dT}$ as a function of temperature.

The permeability $\mu^{\prime}$ increases monotonically upto $\mathrm{x}=0.6$ and thereafter decreases. It is quite obvious science the sample above $\mathrm{x}>0.6$ is paramagnetic at room temperature.

Table 1. Data of the lattice parameter (a), X-ray density $\left(d_{x}\right)$, bulk density $\left(d_{B}\right)$, porosity $(P \%)$, Curie temperature $\left(T_{c}\right)$, permeability $\left(\mu^{\prime}\right)$ at frequency $100 \mathrm{KHz}$, of $\mathrm{Co}_{1-\mathrm{x}} \mathrm{Cd}_{\mathrm{x}} \mathrm{Fe}_{2} \mathrm{O}_{4}$ samples sintered at $1050^{\circ} \mathrm{C} / 3 \mathrm{hrs}$.

\begin{tabular}{ccccccc}
\hline Cd content $(\mathrm{x})$ & $\mathrm{a}_{\mathrm{o}}\left(^{\prime}\right)$ & $\mathrm{d}_{\mathrm{x}}\left(\mathrm{g} / \mathrm{cm}^{3}\right)$ & $\mathrm{d}_{\mathrm{B}}\left(\mathrm{g} / \mathrm{cm}^{3}\right)$ & $\mathrm{P} \%$ & $\mathrm{~T}_{\mathrm{c}}(\mathrm{K})$ & $\mu^{\prime}(100 \mathrm{KHz})$ \\
\hline 0.0 & 8.379 & 5.28 & 4.59 & 14 & 728 & 51 \\
0.1 & 8.409 & 5.35 & 4.87 & 8.8 & 683 & 65 \\
0.2 & 8.438 & 5.41 & 5.02 & 7.2 & 613 & 86 \\
0.3 & 8.468 & 5.47 & 5.08 & 7.3 & 563 & 111 \\
0.4 & 8.498 & 5.53 & 5.09 & 8.0 & 491 & 149 \\
0.5 & 8.529 & 5.59 & 5.16 & 7.6 & 413 & 226 \\
0.6 & 8.557 & 5.65 & 5.17 & 8.6 & 353 & 334 \\
\hline
\end{tabular}


From Fig. 5 it is noticed that the real component of permeability $\mu^{\prime}$ is fairly constant with frequency up to certain frequency range and then falls rather rapidly to very low value at high frequency. The higher the permeability the lower the frequency at which $\mu^{\prime}$ falls rather fast indicating ferromagnetic resonance where the imaginary part of the complex permeability, $\mu^{\prime \prime}$ is expected to rise sharply. This really confirms the Snoek's limit (Snoek 1948).

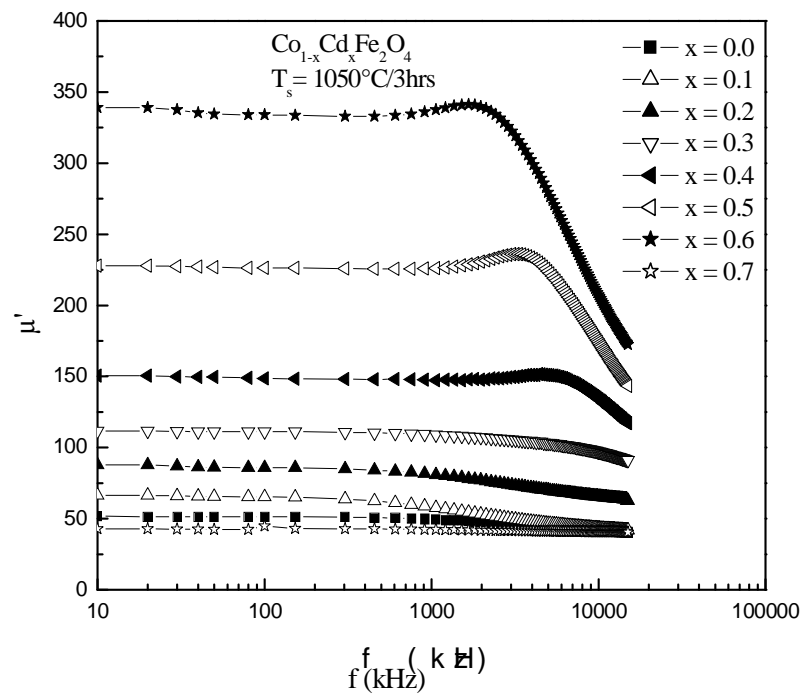

Fig. 5. Frequency dependence of real part of permeability of $\mathrm{Co}_{1-\mathrm{x}} \mathrm{Cd}_{\mathrm{x}} \mathrm{Fe}_{2} \mathrm{O}_{4}$ ferrites sintered at $1050^{\circ} \mathrm{C} / 3$ hours.

\section{CONCLUSIONS}

$\mathrm{Co}_{1-\mathrm{x}} \mathrm{Cd}_{\mathrm{x}} \mathrm{Fe}_{2} \mathrm{O}_{4}$ samples were characterized by X-ray diffraction which confirms the single phase cubic spinel structure. Lattice parameter increases linearly with increasing $\mathrm{Cd}$ concentration .Bulk density increases monotonically with increasing $\mathrm{Cd}$ content signifying that $\mathrm{Cd}$ has a pronounced effect on the densification of the ferrites. The Curie temperatures decrease almost linearly with cadmium substitution due to weakening of AB exchange interaction. From the observation of $\mu^{\prime}-f$ curves for all the samples $\mu^{\prime}$ increases with increasing $\mathrm{Cd}^{2+}$ content up to $\mathrm{x}=0.6$ and obeys the Snoek's limit and and thereafter decreases. It is quite obvious science the sample above $x>0.6$ is paramagnetic at room temperature.

\section{ACKNOWLEDGMENTS}

Authors acknowledge to the Department of Physics, Khulna University of Engineering and Technology, Khulna-9203 and Materials Science Division, Atomic Energy Center, Dhaka-1000 for providing support to carry out of this work. 


\section{REFERENCES}

Abdeen, A. M., O. M. Hemeda, E. E. Assem and M. M. El-Sehly. 2002. Structural, electrical and transport phenomena of Co ferrite substituted by Cd. J. Magn. Magn. Mater. 238: 75.

Arulmurugan, R., G. Vaidyanathan, S. Sendhilnathan and B. Jeyadevan. 2005. Co-Zn ferrite nanoparticles for ferrofluid preparation : Study on magnetic properties. Phyca B 363: 225.

Augustin, C. O., D. Prabhakaran and L. K. Srinivasan. 1993. Fabrication and characterization of $\mathrm{NiCr}_{2} \mathrm{O}_{4}$ spinel. J. Mater. Sci. Lett. 12: 383.

Bayoumi, W. 2007. Structural and electrical properties of zinc-substituted cobalt ferrite. J. Mater Sci. 42: 8254

Chikazumi, S. 1966. Physics of Magnetism. John Wiley, Inc., New York.

Ghani, A. A., A. A. Sattar and J. Pierre. 1991. Composition dependence of magnetization in $\mathrm{Co}_{1-}{ }_{\mathrm{x}} \mathrm{Cd}_{\mathrm{x}} \mathrm{Fe}_{2} \mathrm{O}_{4}$ ferrites. J. Magn. Magn. Mater. 97: 141.

Globus, A., H. Pascard and V. Cagan. 1977. Distance between magnetic ions fundamental properties in ferrites. J. Physique (call) 38: C1-163.

Goldman, A. 1999. Hand book of Modern Ferromagnetic Materials. Kulwer Academic Publishers, Boston, USA.

Jain, G. C., B. K. Das, R. S. Khanduja and S. C. Gupta. 1976. Effect of intragranular porosity of initial permeability and coercive force in a manganese zinc ferrite. J. Mater. Sci. 11: 1335.

Nelson, J. B. and D. P. Riley. 1945. An experimental investigation of extrapolation methods in the derivation of accurate unit-cell dimensions of crystals. Proc. Phys. Soc. London 57: 160.

Snoek, J. L. 1948. Dispersion and absorption in magnetic ferrites at frequencies above one Mc/s. Physica 14(4): 207.

Srivastava, M., S. N. Shringi, R. G. Srivastava and N. G. Nandikar. 1976. Magnetic ordering and domain-wall relaxation in zinc-ferrous ferrite. Phys. Rev. B. 14: 2032.

Vegard, L. 1921. Die Konstitution Der Mischkristalle Und die Raumfüllung Der Atome. Zeitschrift für Physik 5: 17.

Verma, A. and R. Chatterjee. 2006. Effect of Zinc concentration on the structural, electrical and magnetic properties of mixed $\mathrm{Mn}-\mathrm{Zn}$ and $\mathrm{Ni}-\mathrm{Zn}$ ferrites synthesized by the citrate precursor technique. J. Magn. Magn. Mater. 306: 313.

Yafet, Y. and C. Kittel. 1952. Antiferromagnetic arrangements in ferrites. Phys. Rev. 87: 290.

(Received revised manuscript on 15 September, 2011) 